\title{
Study of Peripheral Bone Mineral Density in Patients with Diffuse Idiopathic Skeletal Hyperostosis
}

\author{
M. Di Franco, M. T. Mauceri, A. Sili-Scavalli, A. Iagnocco and A. Ciocci \\ Rheumatology Unit, Department of Medical Therapy, University of Rome 'La Sapienza', Rome, Italy
}

\begin{abstract}
Diffuse idiopathic skeletal hyperostosis (DISH) is an ossifying systemic enthesopathy which involves not only the spine but which may also appear in other sites. Degenerative, inflammatory and metabolic factors have been reported for a possible pathogenic role in the new bone growth that characterises DISH. In the present study peripheral bone mineral density (BMD) has been measured in patients affected by DISH and the results compared to those of a control group. Forty-two patients (33 females and 9 males) affected by DISH and 84 controls (66 females and 18 males) were examined. All subjects underwent radiological study of the lumbar and dorsal spine and the pelvis. BMD was evaluated using dual-energy X-ray absorptiometry and the examination was performed in the distal radius. In DISH patients the mean value of BMD was significantly higher than in controls $(P<0.002)$, even when it was referred to sex subgroups. Statistical analysis showed significant differences between both the two male groups $(P<0.002)$ and the two female groups $(P<0.01)$. In the two female subgroups (DISH patients and controls) BMD was significantly inversely related to age and to the duration of the postmenopausal period. The present study showed higher BMD in DISH patients than in the control group.
\end{abstract}

Keywords: Bone mineral density; Diffuse idiopathic skeletal hyperostosis; Dual-energy X-ray absorptiometry

Correspondence and offprint requests to: Dr Manuela Di Franco, Via Carlo Citerni n.31, 00154 Rome, Italy. Tel: 06/5750228.

\section{Introduction}

Diffuse idiopathic skeletal hyperostosis (DISH) is an ossifying systemic enthesopathy which involves the ligaments, tendons at their bone insertions, capsules and the anulus fibrosus of the intervertebral discs. Hyperostosis typically involves the spine, but may also appear in other sites [1,2]. Its aetiology is unknown. There are many hypotheses as to the possible role of various pathogenic factors: degenerative, inflammatory and metabolic (relationship with mellitus diabetes) factors have all been reported in early studies [3-5]. The presence of local osteogenic hyperactivity has been already suggested [6]. More recently it has been suggested that systemic metabolic factors may be involved in the new bone growth that characterises the disease. On the other hand, the presence of such systemic factors has been hypothesised also in primary osteoarthritis (OA); in fact, increased skeletal concentrations of insulin-like growth factor I, insulin-like growth factor II and transforming growth factor $\beta$ have been considered as possible mechanisms that increase bone density in OA [7]. Although DISH is often considered to be a variant of OA, diarthrodial joints are not involved, intervertebral joints spaces are preserved and apophyseal joints appear to be normal. On the other hand, DISH shows some similarities with OA: for instance, a particular type of hyperostotic hip OA with a remarkable construction has been shown to be associated with DISH [8].

Some studies [9] have reported increased values of bone mineral density (BMD) in OA with respect to osteoporosis (OP). The same result was found when comparing patients with OA to normal subjects $[10,11]$. This finding may be justified by the presence of different 
pathogenic factors that affect bone mass, confirming the already reported inverse association between the risk of $\mathrm{OA}$ and that of OP [12].

To our knowledge, only certain authors [18] have studied bone mineral density (BMD) in DISH patients with respect to controls without finding any significant difference in BMD between the two groups. For this reason we investigated the relationship between DISH and BMD and the results were compared to age- and sexmatched healthy controls. We also evaluated calciumphosphorus changes in both DISH patients and controls.

\section{Methods}

A total of 42 consecutive caucasian patients affected by DISH were studied after giving their informed consent. The diagnosis of DISH was made according to Utsinger's criteria of 1985 [13]. The subjects were 33 females (mean age 63.6 \pm 7.3 years, range $48-77$; mean time since menopause $159.2 \pm 91.4$ months, range 12 372 ) and 9 males (mean age $64.3 \pm 6.4$ years; range $51-$ 73). Eighty-four healthy caucasian subjects were studied as a control group, randomly selected from the general population. These were 66 females (mean age $63.0 \pm 6.8$ years, range 47-77; mean time since menopause $148.3 \pm$ 65.1 months, range 12-324) and 18 males (mean age $64.5 \pm 6.8$ years, range 51-77), and were matched with our patients' sex, age and time since menopause (Table 1). In the female subgroups the time since menopause showed no statistical difference. The two groups (DISH patients and healthy subjects) had a similar type of physical activity, which was light or moderate in all cases, and body mass index values that were without statistical significance. Both the DISH and the healthy groups had no history of fractures secondary to osteoporosis, and no drugs known to alter bone metabolism had been taken. Seven of the DISH patients were affected by diabetes mellitus type II; three of them were treated with diet and four with oral anti-diabetic drugs. In the control group the subjects with symptomatic OA were excluded from the study. Renal function was normal in both groups.

A further 19 females (mean age $60.8 \pm 6.7$ years, range 48-70; mean time since menopause $128.2 \pm 82.2$ months, range 12-264) and 9 males (mean age $63 \pm 6.4$ years, range 51-73) with normal BMD values were selected from among the DISH groups.

We then selected 24 females (mean age $59.6 \pm 6.8$ years, range 47-75; mean time since menopause $110.6 \pm$ 68.7 months, range 12-324) and 16 males (mean age $63.3 \pm 6.5$ years, range $51-73$ ) with normal BMD values from among the healthy groups, matching them with our patients' sex, ages and time since menopause; the age and time since menopause showed no statistically significant difference between the two groups.

All of our subjects underwent dorsolumbar and pelvic radiographs (anteroposterior and lateral) and dual X-ray absorptiometry of the non-dominant forearm.

\section{Bone Mineral Density}

BMD was studied using dual-energy X-ray absorptiometry (DEXA), with dedicated software for the study of the upper extremities (TURBOSCAN-DEXA Nim). The examinations were performed in the distal radius of the non-dominant forearm (Fig. 1). The precision error was $0.7 \%$ and the reproducibility error was $0.5 \%$. The normal value of BMD, at distal radius level, was more than 336
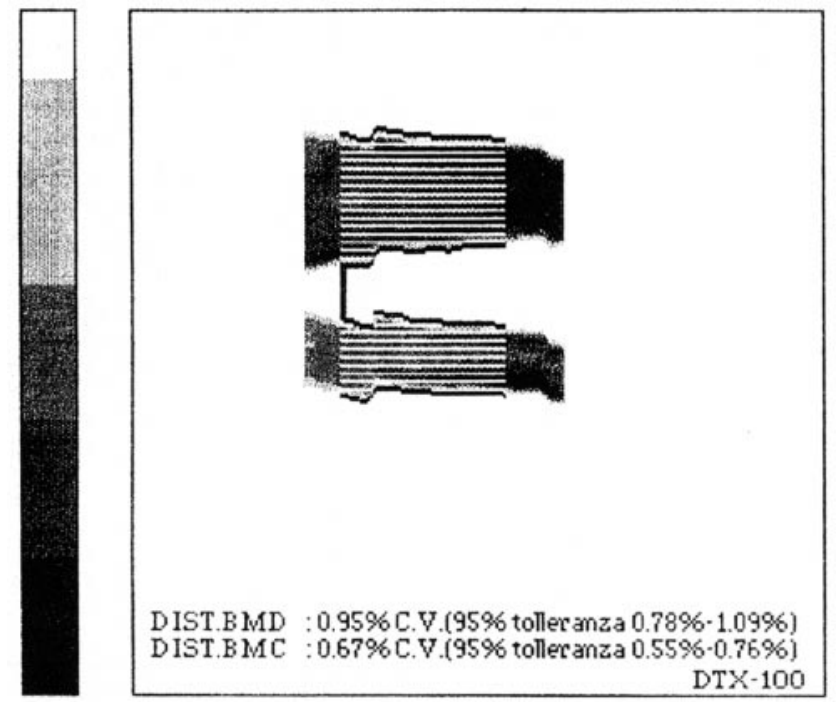

Fig. 1. Radius level of measurement (TURBOSCAN-DEXA Nim).

Table 1. Characteristics of study groups

\begin{tabular}{|c|c|c|}
\hline & DISH & Controls \\
\hline Number of cases & 42 & 84 \\
\hline Males/females & $9 / 33$ & $18 / 66$ \\
\hline Age $($ years; mean $\pm \mathrm{SD})(\min / \max )$ & $63.8 \pm 7.0(48 / 77)^{*}$ & $63.4 \pm 6.8(47 / 77)^{*}$ \\
\hline Age males (years; mean \pm SD) $(\min / \max )$ & $64.3 \pm 6.4(51 / 73) *$ & $64.5 \pm 6.8(51 / 77)^{*}$ \\
\hline Age females (years; mean \pm SD) $(\min / \max )$ & $63.6 \pm 7.3(48 / 77)^{*}$ & $63 \pm 6.8(47 / 77)^{*}$ \\
\hline Time since menopause (months; mean \pm SD) & $159.2 \pm 91.4^{*}$ & $148.3 \pm 65.1 *$ \\
\hline Time since menopause (months; $\min / \max$ ) & $12 / 372 *$ & $12 / 324^{*}$ \\
\hline Body mass index (males/females) & $27.0 \pm 0.2 / 26.8 \pm 2.0 *$ & $27.4 \pm 1.7 / 26.7 \pm 2.6^{*}$ \\
\hline
\end{tabular}

$* P$ value $=$ NS $($ Wilcoxon uncoupled test $)$. 
$\mathrm{g} / \mathrm{cm}^{2}$ and $341 \mathrm{~g} / \mathrm{cm}^{2}$ respectively for the female and male groups. All measurements were performed by the same operator.

\section{Biochemical Measurements}

After an overnight fast blood and 24-hour urine specimens were obtained for the determination of serum calcium $(\mathrm{Ca})$, phosphorus $(\mathrm{P})$, alkaline phosphatase (ALP), osteocalcin (OC) and urine hydroxyproline (OH-Pro). Fasting blood was collected from each subject between 09:00 and 09:30 a.m. Samples were stored at $-70{ }^{\circ} \mathrm{C}$ before measurement. Serum measurements were performed using the following methods: total $\mathrm{Ca}$ concentration by colorimetric photometry; inorganic $\mathrm{P}$ by ultraviolet photometry; ALP by enzymatic colorimetry; and $\mathrm{OC}$ by radioimmunoassay. Urine $\mathrm{Ca}$ and $\mathrm{OH}-$ Pro were all tested by means of colorimetric photometry after 3 days of diet without collagen and standard calcium intake (Table 2).

\section{Statisticala Analysis}

Wilcoxon's uncoupled data analysis was performed to assess the difference between groups. Spearman's rank correlation test was performed to determine whether any correlation existed. Data are presented as mean \pm standard deviation (SD) and range.

The data for all patients were entered on a $\mathrm{PC}$ into a Statgraphics database (STSC Inc., USA).

\section{Results}

The dorsolumbar and pelvic radiographs demonstrated the absence of any deformity or fracture of the vertebral bodies and the pelvis in both groups (patients and healthy subjects).

Among the 33 females with DISH we found that BMD correlated negatively with age $(r=-0.5280, P<0.003)$ and months since menopause $(r=-0.3933, P<0.03)$. Among the 66 healthy female subjects BMD also correlated negatively with age $(r=-0.4689, P<0.0002)$ and months since menopause $(r=-0.4946, P<0.0001)$. In the two male groups (DISH patients and controls) BMD did not correlate with age.

We found that DISH patients had higher mean BMD values than did the control group $\left(401.2 \pm 100.5 \mathrm{~g} / \mathrm{cm}^{2}\right.$ vs $341.8 \pm 74.2 \mathrm{~g} / \mathrm{cm}^{2} ; P<0.002$ ); in particular, the 33 female DISH patients had higher mean BMD values than the female controls $\left(363.8 \pm 69.8 \mathrm{~g} / \mathrm{cm}^{2}\right.$ vs $324.2 \pm 60.8$ $\mathrm{g} / \mathrm{cm}^{2} ; P<0.01$ ) (Table 3). The 9 DISH males also had higher average BMD than healthy male subjects $(538.5 \pm$ $72.9 \mathrm{~g} / \mathrm{cm}^{2}$ vs $\left.402.1 \pm 85.7 \mathrm{~g} / \mathrm{cm}^{2} ; P<0.002\right)$. To evaluate the statistical significance between the DISH and the control groups with normal BMD values (more than $336 \mathrm{~g} / \mathrm{cm}^{2}$ for the females and $341 \mathrm{~g} / \mathrm{cm}^{2}$ for the males) we carried out the Wilcoxon test for uncoupled data and found that the DISH males had a higher average BMD than healthy subjects $\left(538.5 \pm 72.9 \mathrm{~g} / \mathrm{cm}^{2}\right.$ vs 428.2 $\left.\pm 59.8 \mathrm{~g} / \mathrm{cm}^{2} ; P<0.003\right)$, as did the DISH females $\left(412.8 \pm 43.3 \mathrm{~g} / \mathrm{cm}^{2}\right.$ vs $\left.384.5 \pm 40.6 \mathrm{~g} / \mathrm{cm}^{2} ; P<0.02\right)$.

We found no significant difference in serum $\mathrm{Ca}, \mathrm{P}$, ALP, OC and urine OH-Pro between DISH patients and controls.

Table 2. Results of biochemical measurements

\begin{tabular}{lcccc}
\hline & DISH & Controls & Normal values & $P$ value* \\
\hline $\mathrm{Ca}$ & $9.1 \pm 0.5$ & $9.3 \pm 0.6$ & $8.6-10.6 \mathrm{mg} / \mathrm{dl}$ & $\mathrm{NS}$ \\
$\mathrm{P}$ & $3.7 \pm 0.4$ & $3.6 \pm 0.3$ & $3.0-4.5 \mathrm{mg} / \mathrm{dl}$ & $\mathrm{NS}$ \\
Ur. Ca & $216.5 \pm 25.6$ & $219.5 \pm 26.2$ & $100-300 \mathrm{mg} / 24 \mathrm{~h}$ & $\mathrm{NS}$ \\
ALP & $122.1 \pm 22.9$ & $121 \pm 23.3$ & $50-190 \mathrm{U} / \mathrm{l}$ & $\mathrm{NS}$ \\
OC & $8.9 \pm 1.4$ & $9 \pm 1.3$ & $2-14 \mathrm{ng} / \mathrm{ml}$ & $\mathrm{NS}$ \\
OHpr. & $11.7 \pm 4.5$ & $11.9 \pm 2$ & $6-22 \mathrm{mg} / 24 \mathrm{~h} / \mathrm{m}^{2}$ & $\mathrm{NS}$ \\
\hline
\end{tabular}

*Wilcoxon uncoupled test.

Table 3. Results of BMD measurement

\begin{tabular}{lrrrrr}
\hline & \multicolumn{2}{c}{ No. } & DISH & Controls \\
& DISH/Contr. & & \\
\hline BMD in all males & 9 & 18 & $538.5 \pm 72.9$ & $402.1 \pm 85.7$ \\
BMD in all females & 33 & 66 & $363.8 \pm 69.8$ & $324.2 \pm 60.8$ & $<0.002$ \\
BMD in males with normal values*** & 9 & 16 & $538.5 \pm 72.9$ & $428.2 \pm 59.8$ & $<0.01$ \\
BMD in females with normal values** & 19 & 24 & $412.8 \pm 43.3$ & $384.5 \pm 40.6$ & $<0.003$ \\
\end{tabular}

$\mathrm{BMD}\left(\mathrm{g} / \mathrm{cm}^{2}\right)$ : mean $\pm \mathrm{SD}$; measured at distal radius.

*Wilcoxon uncoupled test.

** Subgroups whose data are included in the normal values of the technique used for the measurement of BMD (n.v.: for males: more than 341 $\mathrm{g} / \mathrm{cm}^{2}$; for females: more than $336 \mathrm{~g} / \mathrm{cm}^{2}$ ). 


\section{Discussion}

Our study showed significant higher BMD in DISH patients than in controls, and the mean value of BMD was higher in both male and female patients with DISH. Also, when we considered patients and control subjects with normal BMD values we found significantly higher BMD in DISH patients.

We chose to measure BMD at the distal radius to avoid overestimation, because this site is not usually involved in OA and DISH. Some studies have shown that the measurement of BMD at the distal radius (representing predominantly trabecular bone) was significantly higher than at proximal level (representing predominantly cortical bone) in women with $\mathrm{OA}$ $[14,15]$; this finding could be partly explained by the higher metabolic activity in trabecular bone [16]. However, another study showed increased BMD in women with OA at both cortical and trabecular sites in the radius [17].

To our knowledge, before our study only Troillet et al. [18] measured BMD in DISH patients and in healthy controls, but they found no significant difference in BMD between the two groups. In contrast, for the first time we have shown higher BMD in DISH patients than in controls. This could be explained by the dissimilar characteristics of the groups (higher number of females in our study); by the different sizes of the study groups; or by the different techniques used to measure BMD.

In a case report other authors [19] showed highturnover osteoporosis in a patient with DISH and superficial bladder cancer. Therefore, in this case the coexistence of DISH and OP was probably influenced both by the underlying disease and the therapy, even though the relationship between DISH and OP has not so far been investigated.

Instead, many studies have been performed concerning $\mathrm{OA}$ and BMD. In recent reports [11] densitometric physical and histomorphometric analysis of bone samples taken from iliac crest in patients affected by OA showed high BMD. The findings showed the global skeletal involvement in $\mathrm{OA}$, being the changes present not only at the affected joints but also in other articular areas. More recent studies have confirmed these findings [20-22].

The Rotterdam Study [23] showed that BMD was higher in patients with OA and the rate of bone loss was increased in men and women with OA of the knee and the hips; moreover, the age-related bone loss ratio was increased in older patients, suggesting a more pronounced difference in BMD earlier in the life. These findings suggest the presence of metabolic factors that may play an important role in BMD and bone loss ratio. At present, the problem of the inverse relationship between OA and OP has not yet been solved. In fact, other authors have not found increased BMD in OA [2426]. The different results probably depend on the lack of homogeneity between the groups, i.e. the dissimilar modalities of patient and control group selection, such as sex, age, postmenopausal period duration, body mass index, contemporary presence of other diseases and previous therapy. In fact, all these factors act on bone mass and may consequently modify BMD. The different results obtained by the various authors may also depend on the method of studying BMD.

The present study seems to suggest a bone involvement in DISH. Some reports [27] have already highlighted the presence of subchondral osteitis as one of the first changes of the disease. Similar results have been reported in some studies by Resnick and Niwayama [28] and Bonucci [29]. Other studies showed a higher presence of bone growth factors in patients with DISH, and suggested a possible relevant role for those substances in the pathogenesis of the disease [30]. The finding may be confirmed by the presence of hyperostosis in some disorders with a high production of growth factors [7]. In fact, DISH is a diffuse systemic condition in which it is likely that both mechanical and local factors act on the propensity to deposit new bone. Moreover, it seems likely that systemic metabolic factors also have a role in the new bone growth that is characteristic of the disease [30].

In conclusion, to the best of our knowledge, the present study has for the first time shown higher BMD in DISH patients than in a healthy control group. These results need to be confirmed by additional studies with larger groups.

\section{References}

1. Resnick D, Shaul RS, Robins JM. Diffuse idiopathic skeletal hyperostosis (DISH): Forestier's disease with extraspinal manifestation. Radiology 1975;115:515-20.

2. Ciocci A. Aspetti patogenetici della spondilopatia iperostosante (Pathogenetic aspects of diffuse idiopathic skeletal hyperostosis). Reumatismo 1994;46 (Special Number):108-10.

3. Littlejohn GO. Insulin and new bone formation in diffuse idiopathic skeletal hyperostosis. Clin Rheumatol 1985;4:294-300.

4. Digiovanna JJ, Helfgott RK, Gerber LH, Peck GL. Extra-spinal tendon and ligament calcification associated with longterm terapy with etretinate. N Engl J Med 1986;315:1177-82.

5. Abiteboul M, Arlett J, Sarrabay MA, Mazieres B, Thouvenot JF. Etude du métabolisme de la vitamine A au cours de la maladie hyperostatique, de Forestier et Rotés-Querol. Rev Rum 1986;53:143-5.

6. Arlett J, Jacqueline F, Depeyre M. Le hanche dans l'hyperostose vertébrale. Rev Rum Mal Osteoartic 1978;45:17-26.

7. Dequeker J, Mohan S, Finkelman RD, Aerssens J, Baylink DJ. Generalized osteoarthritis associated with increased insulin-like growth factor I and II and transforming growth factor $\beta$ in cortical bone from the iliac crest: possible mechanism of increased bone density and protection against osteoporosis. Arthritis Rheum 1993;36:1702-8.

8. Peyron JG. Osteoarthritis. Clin Orthoped Rel Res 1986;213:1319.

9. Gotfredsen A, Riis BJ, Christiansen C, Rodbro P. Does a single local absorptiometric bone measurement indicate the overall skeletal status? Implications for osteoporosis and osteoarthritis of the hip. Clin Rheumatol 1990;9:193-203.

10. Nevitt MC, Lane NE, Scott JC, Hochberg MC, Pressman AR, Genant HK, Cummings SR and the Study of Osteoporotic Fractures Research Group. Radiographic osteoarthritis of the hip and bone mineral density. Arthritis Rheum 1995;38(7):907-16.

11. Gevers G, Dequeker J, Geusens P, Nyssen-Behets C, Dhem A Physical and histomorphological characteristics of iliac crest bone 
differ according to the grade of osteoarthritis at the hand. Bone 1989;10:173-7.

12. Dequeker J. The relationship between osteoporosis and osteoarthritis. Clin Rheum Dis 1985;11:271-96.

13. Utsinger PD. Diffuse idiopathic skeletal hyperostosis. Clin Rheum Dis 1985;11:325-54.

14. Carlsson A, Nilsson NE, Westlin NE. Bone mass in primary coxarthrosis. Acta Orthop Scand 1979;50:187-9.

15. Price T, Reeve J, Mitchell R, Hesp R. Bone density in generalised osteoarthritis. Ann Rheum Dis 1983;42:227-8.

16. Schlenker RA, Von Seggen WW. The distribution of cortical and trabecular bone mass along the lengths of the radius and ulna and implications for in vivo bone mass measurements. Calcif Tissue Res 1976;20:41-52.

17. Roy YS, Dequeker J, Mulier JC. Bone mass in osteoarthrosis, measured in vivo by photon absorption. J Bone Joint Surg [Am] 1974;56:587-91.

18. Troillet N, Burckhardt P, Gerster JC. Etude controlée du métabolisme phosphocalcique et de la densitométrie osseuse de l'avant-bras au cours de la maladie de Forestier. Rhumatologie 1992;44(7):150-2.

19. Theiler R, Kränzlin M, Zynamon A, Tyndall A, Schmid HP. High turnover osteoporosis and diffuse idiopathic skeletal hyperostosis induced by retinoid therapy in patient with superficial bladder cancer. Br J Urol 1995;76:400-1.

20. Dequeker J, Aerssens J. Bone mineral density and osteoarthritis. Ann Rheum Dis 1993;52:316.

21. Hart DJ, Mootoosamy I, Doyle DV, Spector TD. The relationship between osteoarthritis and osteoporosis in the general population: the Chingford study. Ann Rheum Dis 1994;53:158-62.

22. Peel NFA, Barrington NA, Blumsohn A, Colwell A, Hannon R, Eastell R. Bone mineral density and bone turnover in spinal osteoarthrosis. Ann Rheum Dis 1995;54:867-71.

23. Burger H, Van Daele PLA, Odding E, et al. Association of radiographically evident osteoarthritis with higer bone mineral density and increased bone loss with age. The Rotterdam Study. Arthritis Rheum 1996;39:81-6.

24. Price T, Hesp R, Mitchell R. Bone density in generalised osteoarthritis. J Rheumatol 1987;14:560-2.

25. Reid DM, Kennedy NJS, Smith MA, Tothill P, Nuki G. Bone mass in nodal primary generalised osteoarthritis. Ann Rheum Dis 1984;43:240-2.

26. Knight SM, Ring EFJ, Bhalla AK. Bone mineral density and osteoarthritis. Ann Rheum Dis 1992;51:1025-6.

27. Fournié A. Maladie de Forestier: une forme particulière d'enthésiopathie ossifiante. Press Med 1990;19:844-5.

28. Resnick D, Niwajama G. Entheses and enthesopathy. Radiology 1983;146:1-9.

29. Ciocci A, Mocetti P, Guerrisi R, et al. Studio anatomoradiologico della spondilopatia iperostosante (Anatomo-radiologic study of diffuse idiopathic skeletal hyperostosis). Reumatismo 1987; 39(1):129-131.

30. Dequeker J, Van de Putte L. Disorders of bone, cartilage and connective tissue. In: Klippel JH, Dieppe PA, eds. Rheumatology, London: Mosby, 1994. 